\title{
Adams' bisensory discrete tracking task and the psychological refractory period: A comment
}

\author{
RAYMOND S. NICKERSON \\ DECISION SCIENCES LABORATORY, L. G. HANSCOM FIELD, BEDFORD, MASSACHUSETTS
}

\begin{abstract}
Abstraet
Adams (1962) has reported an experiment designed to test the "single channel" interpretation of the "psychological refractory period" (PRP). The purpose of this note is to challenge the validity of the test and to argue that the results of the experiment are compatible with a "single channel" hypothesis.
\end{abstract}

\section{Adams' Experiment}

The term "psychological refractory period"' has been used to denote the period of time following the presentation of a stimulus during which the presentation of a second stimulus will yield a delayed response. That delays may in fact occur has been demonstrated under a variety of experimental conditions (e.g., Davis, 1956, 1957, 1959, 1962; Marill, 1957; Rubinstein, 1964; Welford, 1959). One type of explanation of this finding, generally referred to as the single-channel hypothesis, is that "an incoming stimulus is subjected to a central decision process before discharge occurs down the motor nerves, and a second stimulus impinging during this decision time is either disregarded, degraded, or delayed in immediate memory until the decision mechanism has been cleared"' (Adams, 1962).

Adams (1962) has reported an experiment which was designed expressly to test this notion. It is not the purpose of this paper to argue either for or against the single channel hypothesis, but rather to challenge the validity of the test which Adams described.

\section{Deseription of Task}

S's task was to attempt to track a discretely varying visual signal with one hand, while simultaneously tracking a discretely varying auditory signal with the other. The visual signal could assume any of three different positions (left, center and right) and the auditory signal any of three frequencies (600-,800-, and $1000-\mathrm{cps}$ ). The response instrument (one for each hand) was a 2-in control stick which was always in one of three states (electrically) depending on its position in its arc. Signals, in each modality, were repetitive sequences of the three possible events, requiring $S$ simply to move the controls back and forth. The signals occurred in pairs, with the auditory signal either simultaneous with or following the visual; the same visual and auditory events being always paired together. Event uncertainty was not a characteristic of the task.

The interval between successive visual signals was $1.5,2.0$, or 2.5 sec., the different values occurring in random order. The interval between a visual signal and its associated auditory signal $\left(\mathrm{S}_{\mathrm{V}}-\mathrm{S}_{\mathrm{A}}\right.$ interval) was $0,100,200,400$ or $800 \mathrm{msec}$., and the independent variable of interest was the temporal uncertainty resulting from the relative frequencies with which the different $\mathrm{S}_{\mathrm{V}}-\mathrm{S}_{\mathrm{A}}$ intervals were allowed to occur. Specifically, Adams defined three (high, medium and low) time uncertainty conditions, but for the sake of this note we need consider only the extreme cases. In the high uncertainty condition, each of the five possible $\mathrm{S}_{\mathrm{V}}-\mathrm{S}_{\mathrm{A}}$ intervals occurred with equal frequency in each experimental session. In the low uncertainty case, the 100 msec. interval occurred on $80 \%$ of the trials and the other four intervals on $5 \%$ each.

$\mathrm{S}$ was provided with continuous feedback information with respect to both modalities, and, as in the conventional pursuit tracking situation, his task was to maximize time on target. The primary dependent variable was $R T$, but as Adams noted, this is not to be equated with the RT of the familiar RT experiment in which anticipatory (pre-signal) responses are discouraged. The frequency of anticipatory responses was, in fact, high, as might be expected given the nature of the task. The performance measure was algebraic RT, a positive sign being assigned when the response preceded its associated signal, and a negative sign when it followed it.

\section{Results and Conelusions}

It was found that "decrement in response to the second of two closely spaced stimuli was greatest when the stimulus series had high time uncertainty, and was reliably less when time uncertainty was moderate or low." The results were considered to be problematic for single channel theory, and favorable to an "expectancy" interpretation of PRP. Specifically, it was contended that the results "suggested that $S$ could process multiple stimulus series when events were certain as to their type and there was sufficient temporal certainty" (Adams, 1964).

\section{Response Strategy}

That the results of this experiment represent a real problem for single channel theory is not clear. Proponents of single channel hypotheses usually, either explicitly or implicitly, have attributed delays to the time required to process, or extract information from, signals (e.g., Welford, 1952; Broadbent, 1958; Hick \& Welford, 1956). From this point of view, if a signal carried little or no information, there is little or no reason to expect it to tie up the central decision mechanism. (The real problem for any theory that attributes delay solely to the information processing demands of signals is not to account for those cases in which non-informative signals do not cause delays, but 
rather to explain those in which they apparently do.) It might be argued that given complete event certainty and sufficient temporal certainty, very little signal processing is required; that is to suggest that under these conditions individual signals make only slight, if any, demands on attention, Having learned the statistical structure of the signal sequence, S's optimal strategy for maximizing on-target time, may be to simply adjust his inter-response $\left(R_{V}-R_{A}\right)$ time to correspond to the mean or most likely $\mathrm{S}_{\mathrm{V}}-\mathrm{S}_{\mathrm{A}}$ delay, rather than to attend to each individual audio signal before making its associated response. Adams suggested the possibility of a response strategy of this type, and seemed willing to consider it to be an instance of "multichannel operation." As an alternative interpretation, we propose the conjecture that such a response strategy is exactly that which would allow a single channel device to cope with the task.

A further indication that S's response strategy was aimed at smoothing overall performance rather than at minimizing individual $R T s$ is the fact that $\mathrm{RT}_{\mathrm{V}}$ increased with the duration of the $\mathrm{S}_{\mathrm{V}^{-}}-\mathrm{S}_{\mathrm{A}}$ interval over the PRP range. Possibly $S$ attempted to simplify the tracking task intentionally coordinating left and right hand responses. Elsewhere Adams \& Creamer (1962) discussed this possibility and presented evidence that at least in one self-paced bisensory tracking situation the frequency of synchronized responses tended to increase with practice, suggesting the development of a strategy which, if not optimal, at least under some conditions and for some Ss, appeared to be a preferred method of performing the task. (It should be noted that on the basis of the results of their experiment Adams and Creamer concluded "that the human operator can be considered a one-channel system providing this channel is taken to be concerned with the resolution of event uncertainty."')

\section{Temporal Uncertainty}

Although Adams stressed its importance in determining the outcome of his experiment, the role of temporal uncertainty per se was equivocal. In the low uncertainty condition the $100 \mathrm{msec}$. interval occurred on $80 \%$ of the trials, and the other intervals on $5 \%$ each. In the high uncertainty case each interval occurred with equal frequency. Had a condition been included in which the longest ( $800 \mathrm{msec}$ ) interval had occurred on $80 \%$ of the trials, and the other intervals on $5 \%$ each, the temporal uncertainty (at least that which is attributable to the clock time variability of the stimuli) would have been equivalent to that of his low uncertainty condition; however, it seems doubtful that the same relationship would obtain becween $\mathrm{RT}_{\mathrm{A}}$ and the duration of the interval. Rather we would expect that an expectancy would be developed for the longest interval and when a brief one occurred $\mathrm{RT}_{\mathrm{A}}$ would be considerably increased (Mowrer, 1940). In this case it might be argued that the important factor is not the a ve rage uncertainty per interval over a sequence, but the uncertainty of particular intervals within a sequence.
An interval with a high probability of occurrence is less uncertain and hence evokes a shorter RT than an interval with a low probability of occurrence. However, this argument would lead us to expect (1) that minimal RTs would be associated with the most probable interval, irrespective of its duration, and (2) that RT would be independent of interval when all intervals were equiprobable. Neither of these outcomes is consistent with the findings.

That expectancy can be a major determinant of RT must be considered a well established fact (Mowrer, 1940; Wundt, as described in Mowrer, 1940; Klemmer, 1956, 1957; Karlin, 1959; Drazin, 1961; Nickerson, 1965). The question which remains, and which Adams's experiment does not resolve, is whether the delays encountered in PRP type experiments can be accounted for sole $1 \mathrm{y}$ in terms of expectancy-even in those cases in which temporal uncertainty is the only type of uncertainty associated with the task.

\section{References}

Adams, J. A. Test of the hypothesis of psychological refractory period. J. exp. Psychol., 1962, 64, 280-287.

Adams, J. A. Motor skills. Annu. Rev. Psychol., 1964, 15, 181-197. Adams, J. A., \& Creamer, L. R. Data processing capabilities of the human operator. J. engng. Psychol., 1962, 1, 150-158. Broadbent, D. E. Perception and communication. New York: Pergamon, 1958.

Davis, R. The limits of the "psychological refractory period." Quart. J. exp. Psychol., 1956, 8, 24-38.

Davis, R. The human operator as a single channel information system. Quart. J. exp. Psychol., 1957, 9, 119-129.

Davis, R. The role sf "attention" in the psychological refractory period. Quart. J. exp. Psychol., 1959, 11, 211-220.

Davis, $\mathbf{R}$. Choice reaction times and the theory of intermittency in human performance. Quart. J. exp. Psychol., 1962, 14, 157-166.

Drazin, D. R. Effects of foreperiod, foreperiod variability, and probability of stimulus occurrence on simple reaction time. J. exp..Psychol., 1961, 62, 43-50.

Hick, W. E., \& Welford, A. T. Two comments on the paper by Alick Elithorn and Catherine Lawrence. Quart. J. exp. Psychol., $1956,8,39-41$.

Karlin, L. Reaction time as a function of foreperiod duration and variability. J. exp. Psychol., 1959, 58, 185-191.

Klemmer, R. T. Time uncertainty and simple reaction time. $J$. exp. Psychol., 1956, 51, 179-184.

Klemmer, E. T. Simple reaction time as a function of time uncertainty. J. exp. Psychol., 1957, 54, 195-200.

Marill, T. The psychological refractory phase. Brit. J. Psychol., 1957, 48, 93-97.

Mowrer, O. H. Preparatory set (expectancy)-some methods of measurement. Psychol., Monogr., 1940, 52, No. 233.

Nickerson, R. S. Response time to the second of two successive signals as a function of absolute and relative duration of intersignal interval. Percept. mot. Skills, in press.

Rubinstein, L. Intersensory and intrasensory effects in simple reaction time. Percept. mot. Skills, 1964, 18, 159-172.

Welford, A. T. The 'psychological refractory period' and the timing of high-speed performance-a review and a theory. Brit. J. Psychol., 1952, 43, 2-19.

Welford, A. T. Evidence of a single-channel decision mechanism limiting performance in a serial reaction task. Quart. J. exp. Psychol., 1959, 11, 193-210.

\section{Note}

1. This is ESD-TR-65-224 of the AF Electronic Systems Division, Air Force Systems Command. This research was performed at the Decision Sciences Laboratory as part of Project 7682, “ManComputer Information Processing." Reproduction in whole or in part is permitted for any purpose of the U. S. Government. 